\title{
Impact of Pharmacists' Counseling on Quality of Life in Patients Undergoing Hemodialysis in a Tertiary Care Teaching Hospital
}

\author{
Javedh Shareef ${ }^{\mathrm{a}, \mathrm{c}}$, Kripa G S ${ }^{\mathrm{a}}$, Shashidar Baikunje ${ }^{\mathrm{b}}$
}

\begin{abstract}
Background: Chronic kidney disease (CKD) is a condition characterized by the progressive loss of kidney function over a period of months or years. Hemodialysis is a process that removes metabolic wastes when the kidneys fail to do this work adequately. The present study was an attempt made to assess the impact of pharmacists' counseling on quality of life (QoL) in patients undergoing hemodialysis in Justice K S Hegde Charitable Hospital, Mangalore, Karnataka, India.

Methods: It was a prospective, interventional study carried out for a period of 7 months in a university teaching hospital. A total of 60 patients undergoing hemodialysis were enrolled into the study who were categorized into intervention and control groups by block randomization method. Patients in the intervention group received counseling verbally along with the information leaflet, whereas the control group received the counseling only after the end of the study. The QoL of patients was assessed by using WHOQOL-BREF questionnaire at the baseline and at final follow-up.
\end{abstract}

Results: A total of 60 patients (30 patients in the intervention group and 30 patients in the control group) completed the study. A statistically significant difference in the mean domain score was found between the groups $(\mathrm{P}<0.001)$ on the last follow-up but not at the baseline $(\mathrm{P}>0.05)$. In the study among the four domains, improvement was seen in both psychological $(\mathrm{P}<0.01)$ and physical health $(\mathrm{P}<0.05)$ domain.

Conclusion: Education and counseling by clinical pharmacist in patients undergoing hemodialysis leads to clinically and statistically significant improvement in the QoL of hemodialysis patients in the intervention group as compared to that of control group.

Manuscript accepted for publication November 26, 2014

aDepartment of Pharmacy Practice, N.G.S.M. Institute of Pharmaceutical Sciences, Deralakatte, Mangalore 575018, Karnataka, India

bJustice K S Hegde Charitable Hospital, Deralakatte, Mangalore, Karnataka, India

${ }^{\mathrm{c} C o r r e s p o n d i n g ~ A u t h o r: ~ J a v e d h ~ S h a r e e f, ~ D e p a r t m e n t ~ o f ~ P h a r m a c y ~ P r a c t i c e, ~}$ N.G.S.M. Institute of Pharmaceutical Sciences, Deralakatte, Mangalore 575018, Karnataka, India. Email: javedh.shareef@gmail.com

doi: http://dx.doi.org/10.14740/wjnu188w
Keywords: Quality of life; Chronic kidney disease; World Health Organization Quality of Life questionnaire; Hemodialysis

\section{Introduction}

Chronic kidney disease (CKD) is a pathological condition that is diagnosed on the basis of the presence of proteinuria or decreased glomerular filtration rate (GFR) for a period of 3 months or more. It can be progressive in nature with the decline in kidney function occurring over a period of several months to years that can eventually leads to end-stage renal disease (ESRD) [1].

Prevalence of ESRD has increased more than fivefold since 1980 and more than 100,000 new cases of ESRD were diagnosed in 2003 [2]. Despite technological advances in renal replacement therapy (RRT) to treat CKD during the last decade, there have been no significant improvements in survival. It is estimated that over 1.4 million people worldwide receive RRT to prolong life. Increase in the incidence of ESRD by $8 \%$ annually is a troublesome health problem worldwide. The end-stage kidney disease requires RRT or kidney transplantation, both of which cause an enormous cost to individuals and national health budgets [3]. In CKD, loss of nephrons results in reduction in renal function. The remaining nephrons cope with the increased demand initially. However, progressive loss exceeding beyond the ability of the compensatory mechanisms to cope up results in declined GFR [1]. Complications associated with CKD include fluid and electrolyte abnormalities, anemia, cardiovascular disease, hyperparathyroidism, bone disease and malnutrition [4]. The major risk factors for CKD includes diabetes, hypertension, autoimmune disease, polycystic kidney disease, drug toxicity, urinary tract abnormalities, etc. [5].

Dialysis is initiated in most patients when the GFR falls below $15 \mathrm{~mL} / \mathrm{min}$. The goals of dialysis are to remove toxic metabolites that cause uremic symptoms, correct electrolyte abnormalities, restore acid-base status and maintain volume that leads to an improvement in the QoL and also a decrease in morbidity and mortality associated with ESRD [3]. The various types of RRT include hemodialysis, hemofiltration, hemodiafiltration and peritoneal dialysis. In hemodialysis, the toxic metabolites are transferred from the patient's blood across a semi-permeable membrane to a dialysis solution. Blood is

Articles @ The authors | Journal compilation @ World J Nephrol Urol and Elmer Press Inc ${ }^{\mathrm{TM}} \quad$ | www.wjnu.elmerpress.com

This is an open-access article distributed under the terms of the Creative Commons Attribution License, which permits unrestricted use, distribution, and reproduction in any medium, provided the original work is properly cited 
Table 1. Demographic Distribution of the Study Groups

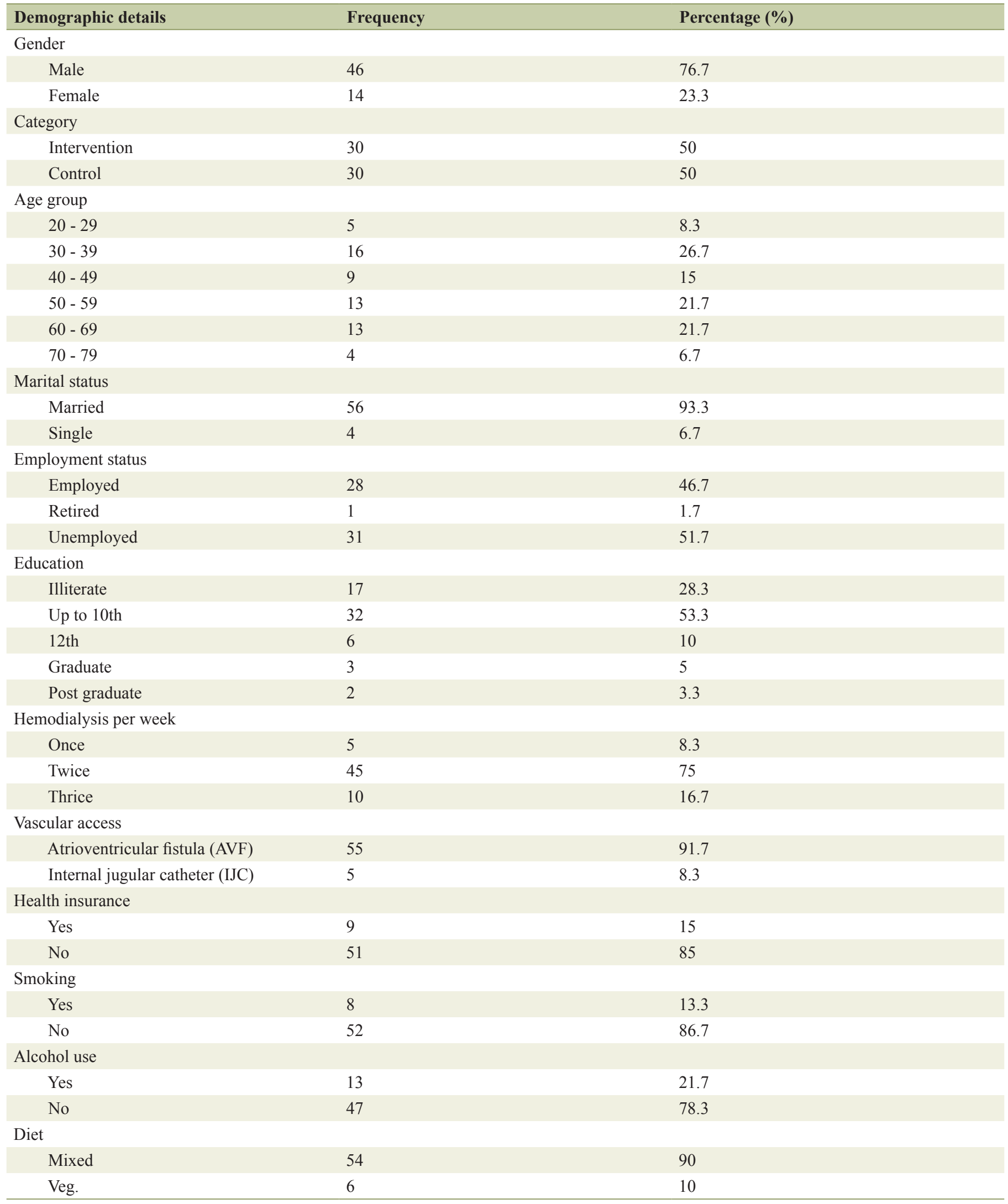


heparinized and diverted through a large central venous cannula line by means of a pump, to the lumen of an artificial kidney (dialyzer) from where it is returned to the patient by another venous line. Maximization of the diffusion gradient is achieved by perfusing the dialysis fluid around the membrane countercurrent to the flow of blood. Common complications of hemodialysis include vascular access infection, hypotension, cardiovascular complications, muscle cramps and pruritus [6].

World Health Organization (WHO) considers health as "a state of complete physical, mental, and social well-being and not merely the absence of disease". It defines QoL as "individuals' perceptions of their position in life in the context of the culture and value systems in which they live and in relation to their goals, expectations, standards and concerns". WHOQOL group has designed a questionnaire to assess the QoL of an individual that is referred to as WHOQOL-BREF questionnaire. The questions were designed taking into consideration the complexities of a person's physical health, psychological state, level of independence, social relationships, personal beliefs and their relationships to salient features of the environment. The questionnaire contains a total of 26 questions with four domains such as physical health, psychological, social relationships and environment domains [7].

Although there are no permanent cure for many diseases especially those that are chronic in nature, it is important to provide palliative treatment and assist them in improving their QoL. Although people with ESRD are now able to live longer due to medical advancements, they often experience many physical changes which can negatively impact on their psychological status and interfere with the quality of their life. The focus of healthcare for these patients has shifted from survival to achieving an acceptable QoL [8]. Various types of interventions like patient education, group participation, and psychiatric counseling have been developed as tools to achieve this goal. In the current study, an attempt has been made to assess if there is an improvement in the QoL of patients with ESRD who visit the hospital for hemodialysis by creating an understanding of the nature of the disease, the importance of regular dialysis, adherence to medication and dietary restrictions.

\section{Methods}

It was a prospective interventional study carried out for a period of 7 months in outpatients undergoing hemodialysis visiting the Nephrology Department at Justice K S Hegde Charitable Hospital, a centrally located 1,200-bed private tertiary care hospital in Dakshina Kannada District, Mangalore, Karnataka, India. The study criteria include: 1) outpatients of either sex with 18 years of age and above who are undergoing hemodialysis; 2) patients who have completed at least 3 months of hemodialysis were selected. Patients who are not willing to participate in the study were excluded from the study.

The study proposal was approved by the hospital human ethical committee. The data collection form was designed as per need of the study so as to record demographic details, laboratory parameters and the medication the patients were on, at the time and during the course of the study. Outpatients visiting the nephrology department for hemodialysis were reviewed by the pharmacist and those patients who met the study criteria were enrolled into the study after obtaining their informed consent. Patients were then categorized into intervention and control groups by block randomization. Permission was obtained from the concerned authors for using the pre-validated WHOQOL-BREF questionnaire. An interviewer-administered abbreviated version of pre-validated WHOQOL-100 (WHOQOL-BREF questionnaire) form in English, Malayalam and Kannada was used to assess the QoL of all patients who participated in the study, to obtain the QoL scores in the domains of physical health, psychological health, social relationship and environment domains before intervention. Domain score of each patient in the group was then totaled and the mean and SD value for the domain before intervention was noted. The value obtained was categorized as the raw score for the domain and was then converted to transformed score in two stages. The intervention group was provided with a patient information leaflet that was primarily focused on the basic functions of kidney, causes and common symptoms of CKD, various treatment modalities, role of hemodialysis in human body, importance of vascular access care, need for adherence to drug therapy and dietary modifications. Patient information leaflet was provided to the patient 1 month after the baseline. The wellbeing of the patient was enquired orally during every visit to the hospital for hemodialysis. Six months into the study both the groups were requested to fill the QoL questionnaire that was evaluated by the same technique explained earlier. The mean and SD value of each domain in both the control group and intervention group was noted at the final followup. Collected information was summarized by using descriptive statistics (mean $\pm \mathrm{SD}$ ), and the influence of counseling on the QoL was determined by comparing the difference between the mean pre- and post-scores of the group that received intervention with similar values obtained for the non-intervention group. $\mathrm{P} \leq 0.05$ was considered significant.

\section{Results}

A total of 60 patients undergoing hemodialysis who met the study criteria were enrolled and all of them completed the study. The study patients were randomized into intervention group $(n=30)$ and control group $(n=30)$ respectively by using block randomization method. All the patients completed all the follow-up and there was no dropout in number of patients in the study. The demographic details of the hemodialysis patients included in the study were shown in Table 1.

Male $(76.7 \%)$ predominance was noted over females $(23.3 \%)$. Most of the patients in our study were in the age range from 30 to 39 years old (26.7\%). Considering the marital, employment and educational status, majority of the patients were married $(53.3 \%)$, unemployed $(51.7 \%)$ and most of them have an educational qualification up to 10th (53.3\%). Concerning hemodialysis per week, most of them were on twice a week (75\%) followed by thrice a week $(16.7 \%)$. The most common vascular access used is AVF (91.7\%) followed by IJC (8.3\%). In relation to health insurance, it was not available to about 
Table 2. ESRD With Co-Morbidities

\begin{tabular}{lll}
\hline ESRD with co-morbidities & Frequency & Percentage (\%) \\
\hline ESRD alone & 4 & 6.7 \\
ESRD with one co-morbidity & 25 & 41.7 \\
ESRD with two co-morbidities & 25 & 41.7 \\
ESRD with three or more co-morbidities & 6 & 10 \\
\hline
\end{tabular}

$85 \%$ of patients. Smoking was infrequent with only $13.3 \%$ of the patients and alcohol use is also less $(21.7 \%)$. Majority of the patients $(90 \%)$ were on mixed diet.

ESRD with co-morbidities were shown in Table 2 and Figure 1.

It was found that ESRD with one and two co-morbidities was highest $(41.7 \%)$ followed by ESRD with three or more co-morbidities (10\%) and ESRD alone (6.7\%).

The drugs were classified according to the system wise classification of British National Formulary (BNF) and were shown in Table 3.

This table shows that according to BNF classification, nutrition and blood products were mainly prescribed $(100 \%)$ for the hemodialysis patients followed by cardiovascular system $(65 \%)$, gastrointestinal system (31.66\%), endocrine system $(25 \%)$, central nervous system (3.33\%) and infection (1.66). Other system wise classifications were found to be nil.

To compare (between group) the difference between intervention and control groups from baseline to final follow-up with respect to each domain, independent sample $t$ test was used and the results were shown in Table 4.

From Table 4, it is cleared that "P" values for all the domains are $<0.05$. Hence there is a difference in mean scores in all the four domains at $5 \%$ level of significance which means that the pharmacists' counseling has an impact on improving the QoL in the intervention group.

To compare the domains within the group (pre-test and post-test), paired " $t$ " test was used and the results were presented in Table 5.

From the table, it is clear that for physical health and psychological domain, the "P" values are $<0.05$. Hence there is a difference in the mean pre-test and post-test for physical health and psychological domain. For social relationship and environment domain, there is no difference $(\mathrm{P}>0.05)$ in the mean pre-test and post-test scores. This means that pharmacists' counseling has an impact on improving the QoL in physical health and psychological domain.

\section{Discussion}

CKD is a public health problem that is of great concern worldwide. Associated morbidities result in major economic strain on the patient and have a negative impact on their QoL. Although the advances in dialysis treatment have contributed to improved survival rates of patients with ESRD, the level of health-related QoL in them is much lower when compared with that of the general population [9].

Impact of pharmacists' counseling on QoL in hemodialysis patients was analyzed domain wise by comparing $\mathrm{QoL}$ scores between the intervention and control groups. To understand the impact of pharmacists' counseling on the difference in QoL, domain scores were observed between the group and within the group during the baseline and final month of followup.

Analysis of the questionnaire of the study population prior to counseling revealed that there was no difference $(\mathrm{P}>0.05)$ in the mean scores with respect to each domain at 5\% significance level between the groups that were to receive intervention and the control. Various studies in patients undergoing hemodialysis have revealed that the health-related QoL is impaired in hemodialysis patients [10-14]. In the current study, evaluation of the difference between the group with respect to each domain using independent sample " $t$ " test, it is found that there was a significant improvement in the mean domain score in the intervention group for all the four domains as compared to the group that was not provided with an intervention. This observation is in agreement with similar results obtained at other centers using a variety of QoL questioners [15-20]. A significant mean score difference $(\mathrm{P}<0.01)$ is indicative that pharmacists' counseling has an impact on improving the QoL in hemodialysis patients.

At the final month of follow-up, the mean score was highest in the psychological domain followed by physical health, environment and social relationship domains. These observa-

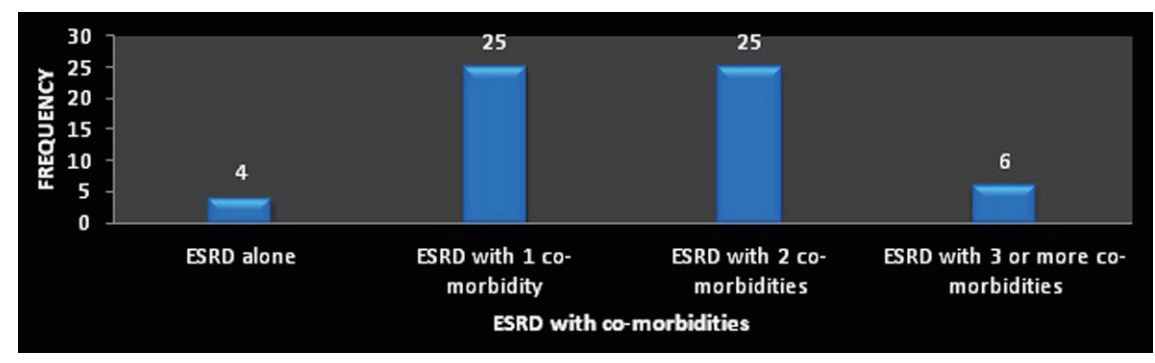

Figure 1. ESRD with co-morbidities. 
Table 3. BNF Classification of Drugs

\begin{tabular}{lll}
\hline BNF classification & Frequency & Percentage (\%) \\
\hline Cardiovascular system & 39 & 65 \\
Central nervous system & 2 & 3.33 \\
Endocrine system & 15 & 25 \\
Gastrointestinal system & 19 & 31.66 \\
Infections & 1 & 1.66 \\
Nutrition and blood & 60 & 100 \\
\hline
\end{tabular}

tions were in agreement with the findings of Suja et al [16]. It is also observed that there is a difference $(\mathrm{P}<0.05)$ in mean pre-test and post-test (final follow-up) values for physical domain and psychological domain in the group that received intervention whereas there was no significant difference $(\mathrm{P}>$ $0.05)$ in social relationship and environment domain. These findings are in agreement with earlier finding [21] which indicates that hemodialysis patients have poorer QoL in several aspects of their environment and social relationship.

The study could be compared with the work done by Suja et al and Thomas et al, where the impact of patient counseling on QoL in patients of hemodialysis was found to be very effective $[15,16]$. Another study done on assessment of the QoL in hemodialysis patients done by Parthasarathi et al [22] found that QoL of hemodialysis was considerably impaired when compared to that of healthy individuals of the general popula- tion as well as of renal transplant patients.

In our study, among the demographic factors, it was found that male patients with ESRD were higher than the female patients. These findings were consistent with several studies conducted on QoL in hemodialysis patients [23-26]. In the current study, majority of the population was found to be aged 30-39 years old. This finding correlates with the study done by Hala Mohammed et al [9] and probably due to the fact that the selffunded hemodialysis treatment in India reserved monthly for the younger ones. Our study findings demonstrated that most of the study samples were married $(93.3 \%)$. These findings are quiet similar to the study undertaken by Theofilou [27] which suggests that better psychological and social wellbeing can be associated with family conditions and living with a partner.

In the current study, it was found that most of the patients are undergoing dialysis twice a week $(75 \%)$. The findings of

Table 4. Result of Independent Sample " $t$ " Test

\begin{tabular}{|c|c|c|c|c|c|}
\hline Domains & Category & Mean & SD & " $t$ " value & P value \\
\hline \multirow[t]{2}{*}{ Domain 1 (physical health) } & Intervention & 10.43 & 3.89 & 13.98 & $<0.001$ \\
\hline & Control & 4.67 & 4.45 & & \\
\hline Domain 2 (psychological) & Control & 1.20 & 4.55 & & \\
\hline Domain 3 (social relationships) & Intervention & 2.47 & 2.68 & 8.90 & $<0.001$ \\
\hline \multirow[t]{2}{*}{ Domain 4 (environment) } & Intervention & 10.87 & 3.58 & 16.81 & $<0.001$ \\
\hline & Control & 6.20 & 4.25 & & \\
\hline
\end{tabular}

Table 5. Result of Paired " $t$ " Test

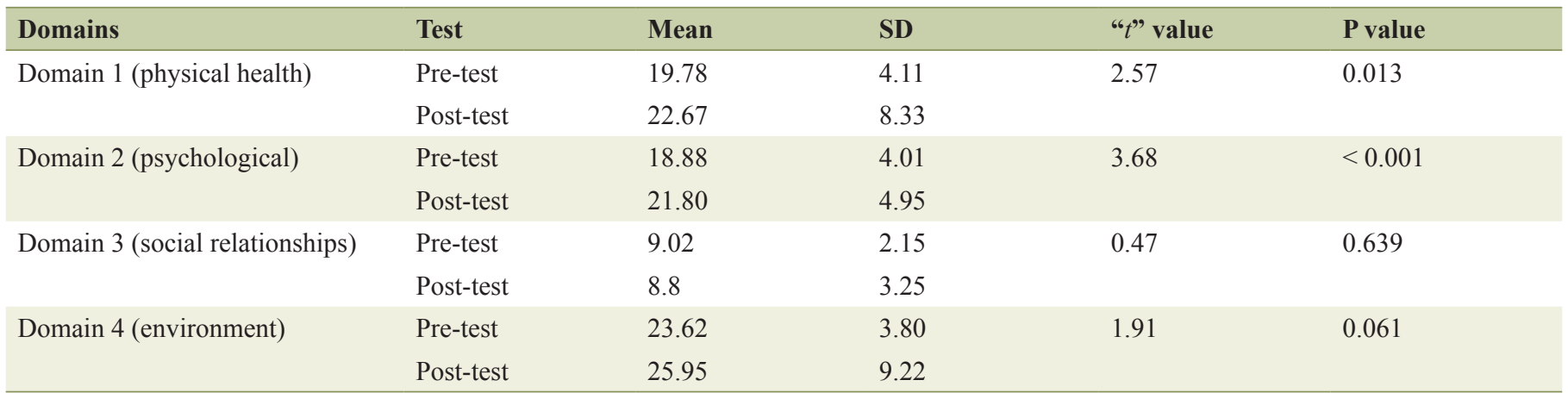


Lok implies that two-thirds of the dialysis patients experienced pain when subjected to needle pricks on each dialysis session which was considered as the highest physical condition experienced by the study subjects. This condition was considered as a significant stressor related to QoL in dialysis patients [28].

The present study revealed that majority of the patients were unemployed $(51.7 \%)$ with basic education up to 10th $(53.3 \%)$. These findings were similar to the study results of Theofilou [27] which highlights that education appears to have an effect on the environment domain, suggesting that more educated patients hold more positive perceptions about their environment. The present study revealed that majority of the study population $(90 \%)$ prefers mixed diet, though the social habits like smoking (13.3\%) and alcohol (21.7\%) were found to be comparatively less. This increased mixed diet and social habits could also be a risk factor for renal disorder when compared to vegetarians. The study findings of Stephen et al [29] found that vegetarians are less likely to get renal disorder than others and social habits indirectly trigger the renal disorder and lower the QoL.

The current study results showed that for patients with ESRD with a single co-morbidity, hypertension (36.7\%) was the most common. The study result was similar to the findings of Suja et al and Yi et al $[16,30]$. Among ESRD with two comorbidities, hypertension with diabetes (23.3\%) was found to be most common and in case of ESRD patients with three or more co-morbidities, hypertension with diabetes and ischemic heart disease (IHD) (5\%) were the most commonly observed disease.

According to BNF classification, the present study showed that the nutrition and blood class (erythropoietin (100\%) and sevelamer $(8.33 \%)$ ) were the most commonly used products in patients on hemodialysis followed by cardiovascular drugs (clonidine $(65 \%)$, torsemide $(61.6 \%)$, amlodipine $(48.3 \%)$ and aspirin $(46.6 \%)$ ). The study done by Lopes et al [31] found an increase in the prescription of antihypertensive agents mainly angiotensin receptor blocker and beta blockers and showed the variations across the countries in prescription of antihypertensive for hemodialysis patients. The other class of drugs commonly used includes gastrointestinal drugs (pantoprazole $(31.6 \%)$ and rabeprazole (1.6\%)), endocrine system drugs (insulin $(25 \%)$ ), infections drug (metronidazole, amikacin and levofloxacin (1.66\%)) and central nervous system drugs (amitriptylline and tramadol (3.3\%)).

There is no clear consensus obtained from QoL studies as to whether a patient feels that hemodialysis or peritoneal dialysis is the better treatment option. There is evidence in literature that supports an argument that peritoneal dialysis is associated with better QoL than the hemodialysis [32-38]; however, there is a report which indicates that there is no such association [39].

Frequent dialysis imposes a considerable burden on the patients and families. Altered socioeconomic status of ESRD patients on hemodialysis is known to influence the QoL. Financial affordability and non-coverage by health insurance schemes appear to be the major factors that affect the overall QoL in patients with ESRD. It was observed in our study, that the majority of the patients $(85 \%)$ were not covered by insur- ance and their dialysis costs were met through charity, family, friends and philanthropic organizations. The study done by Unruh et al [40] found that the costs of hemodialysis in a developing country remained significantly lower compared to developed countries but it still places a burden on patients as most people do not have health insurance coverage. Support from the government, health insurance sector or reimbursement of treatment costs may minimize the economic burden imposed on their family resulting in better outcomes. Pharmacist' assurance and counseling of the patient shows that the disease will be under control by proper adherence to the medication and diet appears to have improved the outcomes. Providing patients with written information regarding the nature of the disease and the best practices that can be adopted by them also appears to have improved the patients QoL.

\section{Conclusion}

The current study aimed to assess the impact of pharmacists counseling on QoL in hemodialysis patients observed that before counseling, that is at baseline there was no significant difference in the domain scores for both intervention and control groups. During the final follow-up, it was observed that between the groups there was a difference in mean scores in the entire four domains which implies that pharmacist education and counseling has led to clinically significant improvement in the QoL of intervention group as compared with that of control group. The study also suggests that the periodic counseling by a clinical pharmacist at regular intervals has a positive impact on improving the QoL of hemodialysis patients.

\section{Acknowledgement}

First of all we would like to thank the authors of WHO-BREF for given permission and providing the questionnaire in English and local languages and in our study. We like to express our gratitude to the head of Department of Nephrology Unit of Justice K S Hegde Charitable Hospital, for the support and encouragement to do this study. We are also very thankful to the Principal, N.G.S.M. Institute of Pharmaceutical Sciences for providing necessary support to the study.

\section{References}

1. Rojer W, Cate W. Clinical Pharmacy and Therapeutics. 4th ed. China: Churchill Livingstone. 2008;232-261.

2. Dipiro JT, Chisholm-Burns MA, Wells BG, Terry LS, Patrick MM, Jill MK, John CR. Pharmacotherapy Principles and Practice. New York: McGraw-hill; 2007;373397.

3. Schieppati A, Remuzzi G. Chronic renal diseases as a public health problem: epidemiology, social, and economic implications. Kidney Int Suppl. 2005;(98):S7-S10.

4. Koda KM, Young LY, Alldredge BK, Corelli RL, Guglielmo BJ, Kradjan WA, et al. Applied therapeutics the 
clinical use of drugs. 9th ed. United States of America: Lipincott Williams and Wilkins;2009;31-33.

5. Punal J, Lema LV, Sanhez-Guisande D, Ruano-Ravina A. Clinical effectiveness and quality of life of conventional haemodialysis versus short daily haemodialysis: a systematic review. Nephrol Dial Transplant. 2008;23(8):26342646.

6. Helms AR, Quan DJ, Herfindal ET, Gourley GK. Textbook of therapeutics drug and disease management.8th ed. United States of America: Lipincott Williams and Wilkins; 2006;1183-1201.

7. WHOQOL Group. Measuring Quality of Life: The development of the World Health Organization Quality of Life Instrument (WHOQOL). Geneva: World Health Organization; 1993.

8. Tallis K. How to improve the quality of life in patients living with end stage renal failure. Ren Soc Aust J. 2005;1(1):18-24.

9. Hala Mohamad Abd El hamed Ali, Nahed Abdel monem Elsebai, Fardous Abdel Fattah Ramadan, Wafaa Ismail Sherif Salam, Tarek Medhat Abbas Abdelhady. Impact of Teaching Guidelines on Quality of Life for Hemodialysis Patients. Nature and Science. 2011;9(8):214-222.

10. Hsieh RL, Huang HY, Chen SC, Lin WH, Wu CW, Chang $\mathrm{CH}$, Lee WC. Changes in physical functional performance and quality of life in hemodialysis patients in Taiwan: a preliminary study. J Nephrol. 2010;23(1):41-48.

11. Germin-Petrovic D, Mesaros-Devcic I, Lesac A, Mandic M, Soldatic M, Vezmar D, Petric D, et al. Health-related quality of life in the patients on maintenance hemodialysis: the analysis of demographic and clinical factors. Coll Antropol. 2011;35(3):687-693.

12. Seica A, Segall L, Verzan C, Vaduva N, Madincea M, Rusoiu S, Cristea S, et al. Factors affecting the quality of life of haemodialysis patients from Romania: a multicentric study. Nephrol Dial Transplant. 2009;24(2):626-629.

13. Bele S, Bodhare TN, Mudgalkar N, Saraf A, Valsangkar S. Health-related Quality of Life and Existential Concerns Among Patients with End-stage Renal Disease. Indian J Palliat Care. 2012;18(2):103-108.

14. Spiegel BM, Melmed G, Robbins S, Esrailian E. Biomarkers and health-related quality of life in end-stage renal disease: a systematic review. Clin J Am Soc Nephrol. 2008;3(6):1759-1768.

15. Thomas D, Joseph J, Francis B, Mohanta GP. Effect of patient counseling on quality of life of hemodialysis patients in India. Pharm Pract (Granada). 2009;7(3):181184.

16. Abraham S, Venu A, Ramachandran A, Chandran PM, Raman S. Assessment of quality of life in patients on hemodialysis and the impact of counseling. Saudi J Kidney Dis Transpl. 2012;23(5):953-957.

17. Pai AB, Boyd A, Chavez A, Manley HJ. Health-related quality of life is maintained in hemodialysis patients receiving pharmaceutical care: a 2-year randomized, controlled study. Hemodial Int. 2009;13(1):72-79.

18. Moattari M, Ebrahimi M, Sharifi N, Rouzbeh J. The effect of empowerment on the self-efficacy, quality of life and clinical and laboratory indicators of patients treated with hemodialysis: a randomized controlled trial. Health Qual Life Outcomes. 2012;10:115.

19. Dashti-Khavidaki S, Sharif Z, Khalili H, Badri S, Alimadadi A, Ahmadi F et al., The use of pharmaceutical care to improve health-related quality of life in hemodialysis patients in Iran. Int J Clin Pharm. 2013;12:1-8.

20. Poppe C, Crombez G, Hanoulle I, Vogelaers D, Petrovic $M$. Improving quality of life in patients with chronic kidney disease: influence of acceptance and personality. Nephrol Dial Transplant. 2013;28(1):116-121.

21. Theofilou P. Quality of life in patients undergoing hemodialysis or peritoneal dialysis treatment. J Clin Med Res. 2011;3(3):132-138.

22. Sathvik BS, Parthasarathi G, Narahari MG, Gurudev KC. An assessment of the quality of life in hemodialysis patients using the WHOQOL-BREF questionnaire. Indian J Nephrol. 2008;18(4):141-149.

23. Fukuhara S, Lopes AA, Bragg-Gresham JL, Kurokawa K, Mapes DL, Akizawa T, Bommer J, et al. Health-related quality of life among dialysis patients on three continents: the Dialysis Outcomes and Practice Patterns Study. Kidney Int. 2003;64(5):1903-1910.

24. Pakpour AH, Saffari M, Yekaninejad MS, Panahi D, Harrison AP, Molsted S. Health-related quality of life in a sample of Iranian patients on hemodialysis. Iran J Kidney Dis. 2010;4(1):50-59.

25. Anees M, Hameed F, Mumtaz A, Ibrahim M, Saeed Khan MN. Dialysis-related factors affecting quality of life in patients on hemodialysis. Iran J Kidney Dis. 2011;5(1):914.

26. Perlman RL, Finkelstein FO, Liu L, Roys E, Kiser M, Eisele G, Burrows-Hudson S, et al. Quality of life in chronic kidney disease (CKD): a cross-sectional analysis in the Renal Research Institute-CKD study. Am J Kidney Dis. 2005;45(4):658-666.

27. Theofilou PA. The Impact of Sociodemographic and Psychological Variables on Quality of Life in Patients with Renal Disease: Findings of a Cross - Sectional Study in Greece. J Clinic Res Bioeth. 2012;3(2):1-5.

28. Lok P. Stressors, coping mechanisms and quality of life among dialysis patients in Australia. J Adv Nurs. 1996;23(5):873-881.

29. Stephen MM, Sivakumar R, Sreedas, Rajesh Joseph. Prospective study on hemodialysis patients and effect of patient counseling on health related quality of life. Indian Journal of Hospital Pharmacy.2012;49:157-161.

30. Tsai YC, Hung CC, Hwang SJ, Wang SL, Hsiao SM, Lin MY, Kung LF, et al. Quality of life predicts risks of end-stage renal disease and mortality in patients with chronic kidney disease. Nephrol Dial Transplant. 2010;25(5):1621-1626.

31. Lopes AA, Bragg-Gresham JL, Ramirez SP, Andreucci VE, Akiba T, Saito A, Jacobson SH, et al. Prescription of antihypertensive agents to haemodialysis patients: time trends and associations with patient characteristics, country and survival in the DOPPS. Nephrol Dial Transplant. 2009;24(9):2809-2816. 
32. Ginieri-Coccossis M, Theofilou P, Synodinou C, Tomaras V, Soldatos C. Quality of life, mental health and health beliefs in haemodialysis and peritoneal dialysis patients: investigating differences in early and later years of current treatment. BMC Nephrol. 2008;9:14.

33. Abreu MM, Walker DR, Sesso RC, Ferraz MB. HealthRelated Quality of Life of Patients receiving Hemodialysis and Peritoneal Dialysis in Sao Paulo, Brazil: A Longitudinal Study. Value in health. 2011;14:119-121.

34. Garcia-Llana H, Remor E, Selgas R. Adherence to treatment, emotional state and quality of life in patients with end-stage renal disease undergoing dialysis. Psicothema. 2013;25(1):79-86.

35. Emad AS, Mohd R. Abdul Manaf. Quality of Life of Caregivers and Patients Undergoing Haemodialysis at Ministry of Health, Jordan. International Journal of Applied Science and Technology. 2012; 2(3):75-85.

36. Zhang AH, Cheng LT, Zhu N, Sun LH, Wang T. Comparison of quality of life and causes of hospitalization between hemodialysis and peritoneal dialysis patients in China. Health Qual Life Outcomes. 2007;5:49.

37. Kutner NG, Zhang R, Barnhart H, Collins AJ. Health status and quality of life reported by incident patients after 1 year on haemodialysis or peritoneal dialysis. Nephrol Dial Transplant. 2005;20(10):2159-2167.

38. Juergensen E, Wuerth D, Finkelstein SH, Juergensen PH, Bekui A, Finkelstein FO. Hemodialysis and peritoneal dialysis: patients' assessment of their satisfaction with therapy and the impact of the therapy on their lives. Clin J Am Soc Nephrol. 2006;1(6):1191-1196.

39. Okpechi IG, Nthite T, Swanepoel CR. Health-related quality of life in patients on hemodialysis and peritoneal dialysis. Saudi J Kidney Dis Transpl. 2013;24(3):519526.

40. Unruh M, Miskulin D, Yan G, Hays RD, Benz R, Kusek JW, Meyer KB. Racial differences in health-related quality of life among hemodialysis patients. Kidney Int. 2004;65(4):1482-1491. 